\title{
Ex-situ TEM: Gaining Fundamental Insights into the Reduction-Oxidation- Reduction (ROR) Process in Small, Bimetallic Particles
}

\author{
C.E. Kliewer ${ }^{1}$, S.L. Soled ${ }^{1}$ and S. Miseo ${ }^{1}$ \\ ${ }^{1 .}$ ExxonMobil Corporate Strategic Research, 1545 Route 22 East, Annandale, NJ
}

Air regeneration of bimetallic catalysts remains an important but poorly understood area of science. The effects of the reduction-oxidation-reduction (ROR) steps on a multi-component material's nanostructure are often unknown. However, with ex-situ electron microscopy-based techniques, ${ }^{1,2}$ new insights into these structure/process variable relationships are possible. Earlier TEM studies conducted using ExxonMobil's ex-situ treatment facility revealed that the air oxidation of solid $\mathrm{Cu}$ particles resulted in the development of $\mathrm{Cu}$ oxide hollow domes (torus structures). ${ }^{3,4,5}$ However, the effect of alloying the $\mathrm{Cu}$ was not examined.

In this study, the reduction, air oxidation, and re-reduction of small, 50/50 atomic percent $\mathrm{CuAu}$ alloy particles was studied. The particles were first formed by high vacuum vapor deposition onto an amorphous, Al oxide-coated carbon support film. The alloy was given a series of ex-situ thermal treatments beginning with an initial $500{ }^{\circ} \mathrm{C}, 1$ hour, $\mathrm{H}_{2}$ anneal. The material was inertly transferred from the treatment facility into the TEM. ${ }^{2}$ The resulting structures consisted of discrete $\mathrm{CuAu}$ alloy particles (Figure 1a). The material was then given a $200{ }^{\circ} \mathrm{C}, 6$ hour, air oxidation treatment. Re-examination of the same particles in the TEM indicated that those particles had developed a core-shell morphology (Figure 1b). Energy dispersive spectrometry (EDS) data indicated that the shells were enriched in $\mathrm{Cu}$ while the particle cores remained enriched in $\mathrm{Au}$. These data suggest that $\mathrm{Cu}$ ions had diffused through the $\mathrm{CuAu}$ alloy matrix to the particles' surfaces and had begun to oxidize, while Au remained within the particles' cores. A subsequent $300{ }^{\circ} \mathrm{C}, 1$ hour, $\mathrm{H}_{2}$ treatment revealed a mix of particles similar to the parent structures and a new population of small $\mathrm{Cu}$-rich particles. Thus, the ROR treatments had significantly changed the original material by creating: (1) bimetallic structures that were slightly depleted in $\mathrm{Cu}$ relative to their parent particles and (2) a new population of small $\mathrm{Cu}$-rich metal particles. Thus, the ROR treatments changed both the metal particle chemistry and the metal particle size distribution. The insights gained via these types of ex-situ studies lend unique understanding to the effects of the air regeneration process on small, bimetallic metal catalyst systems.

References:

[1] L.F. Allard et. al. Proceedings Microscopy \& Microanalysis 3 (1997) 595

[2] C.E. Kliewer et. al. Proceedings Microscopy \& Microanalysis 1 (1999) 926

[3] C.E. Kliewer et. al. Proceedings Microscopy \& Microanalysis 6 (2000) 378

[4] C.E. Kliewer et. al. Proceedings Microscopy \& Microanalysis 7 (2001) 1214

[5] C.E. Kliewer et. al. Microscopy \& Microanalysis 12 (2006) 135-144 


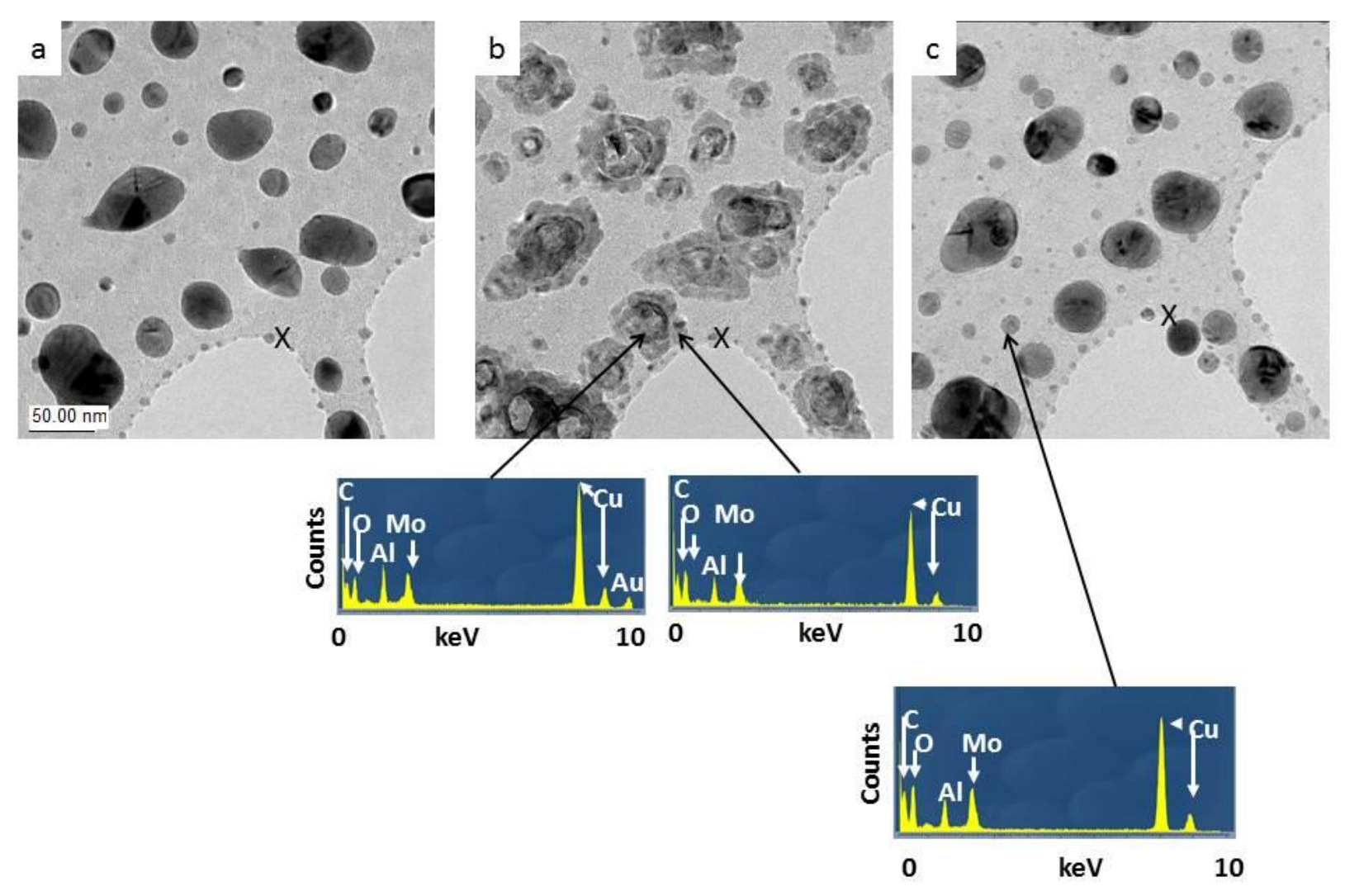

Figure 1. Bright field TEM images reveal $\mathrm{CuAu}$ metal particles supported on an amorphous, aluminum oxide-coated holey carbon film after various ex-situ treatments: (a) $500{ }^{\circ} \mathrm{C}$ for $1 \mathrm{~h}$ under $\mathrm{H}_{2}$, (b) $200{ }^{\circ} \mathrm{C}$ for $6 \mathrm{~h}$ under air, and (c) $300{ }^{\circ} \mathrm{C}$ for $1 \mathrm{~h}$ under $\mathrm{H}_{2}$. The initial reduction treatment (a) presents uniform metal particles across the support film. The oxidation treatment (b) results in the formation of distinct core-shell structures in which the shell is enriched in $\mathrm{Cu}$ and the core is enriched in Au. The final reduction treatment (c) results in uniform $\mathrm{Cu}_{1-\mathrm{x}} \mathrm{Au}$ metal particles and a new population of small, $\mathrm{Cu}$ rich metal particles. 